\title{
KOICA 역량개발 지원사업의 \\ 성과관리 모델 및 프레임워크
}

\section{목차}

I. 문제제기의 배경

II. 역량개발과 제도개선

1. 역량개발과 제도개선의 필요성

2. 세계은행의 역량개발 모델

3. 스웨덴 국제개발협력청(Sida)의 역량개발 평가 결과

4. 세계최고감사기구 개발 이니셔티브(IDI)의 감사 역량개발사업 평가

5. KOICA 우수사례 분석 및 시사점

III. KOICA 역량개발 지원사업의 모델

1. 다년도 역량개발 모델 (MCM)

2. 단계별 성과관리 프레임워크 (PPMf)

3. $\mathrm{MCM}$ 과 $\mathrm{PPMf}$ 관계 및 기타 활용

NV. 활용사례 및 모델 확장

1. 베트남 감사원 역량강화 지원사업 모델 및 프레임워크 운용사례

2. 모델의 확장 및 프레임워크

3. $\mathrm{PDM}$ 과의 비교 및 여타 사업형태에 대한 적용가능성

$\mathrm{V}$. 결어

참고문헌 


\section{초록(Abstract)}

개발도상국의 역량개발을 지원하는 것이 개발원조의 효과를 제고하기 위한 주요한 흐 름 중 하나로 자리 잡아가면서 이에 관한 다양한 연구와 이론 및 방법 등이 시도되어왔 다. $\mathrm{OECD}$ 와 세계은행(World Bank)은 물론 스웨덴 국제개발협력청(Sida), 각국 감사원 의 전문기구인 IDI 등은 하나같이 기존의 역량개발의 지원방식을 반성하면서 개인의 역량 강화를 넘어서 조직과 제도차원의 개선을 통한 역량개발을 강조하고 있으며, 체계적인 연 구를 거듭해 오고 있다. 본고에서는 국제사회에서 최근 논의되고 있는 역량개발에 관하여 살펴보고, 베트남 감사원 역량강화 지원사업을 사례로 수립하여 일정한 성과를 거둔 '다년 도 역량개발 모델(MCM)'과 '단계별 성과관리 프레임워크(PPMf)'의 활용을 제안하고 있 다. 단순명확한 모델과 이를 토대로 목적달성을 위한 과정이 담긴 단계적인 성과관리 프 레임워크를 도움을 받는 수원국과 함께 공유하여 역할분담을 할 경우 수원국의 주인의식 (ownership) 내재화와 역량개발(Capacity Development)이 추구하는 목적인 조직 및 제 도상 혁신에 기여할 수 있을 것이다.

시간 경과와 담당자의 교체 등 협력사업의 현실적으로 어려운 제반 여건에도 불구하고, 역량개발 지원사업의 성과를 일관성 있고 체계적으로 관리하고 역량개발의 효과를 제고하 기 위한 사업관리 툴은 비단 $\mathrm{KOICA}$ 의 다년도 연수사업 외에도 역량개발을 포함한 프로 젝트형 사업도 이를 필요로 하고 있다. 본고를 통하여 이를 위한 실용적인 논의가 이뤄져 우리나라의 개발행정과 연구가 한 단계 성장해 나가기를 희망한다.

\section{I. 문제제기의 배경}

개발 원조를 시행함에 있어서 당초 의도한 개발의 효과를 거양했는지 여부에 대하여 국제사회가 체계적이고 과학적으로 검증하기 시작한 것은 2000년 새천년개발목표(Millenium Development Goals, MDGs)를 설정한 이후의 일이다. 1950년대 초 마샬플랜 이래 30여 년간 원조효과가 지 지부진하자 1980년대에 원조에 대한 회의와 함께 원조의 책임성이 강조되기 시작하였다. 2000년 대에 들어 UN 등 국제사회는 MDGs의 8개 목표(goals)와 18개의 세부목표(targets)를 설정하고, 각 목표에 따른 지표(indicators)를 설정함으로써 $\mathrm{ODA}$ 를 중심으로 한 전세계 개발원조 활동을 체계적으로 모니터링하고 그 진척사항을 점검하며 평가하여 왔다(KOICA ODA교육원, 2012: 250). 즉, 국제사회는 2005년 '원조효과성에 관한 파리선언(Paris Declaration on Aid Effectiveness)', 
2008년 '아크라 행동계획(Accra Agenda for Action)', 2011년 '효과적 개발협력을 위한 부산파 트너십(Busan Partnership for Effective Development Cooperation)'을 통해 원조의 성과를 거시적인 관점에서 점검해 왔으며, 개발원조 사업을 기획, 평가함에 있어서 결과중심의 접근법 (result-base approach)을 강조하고, 무작위대조시험기법(Randomized Controlled Trials, $\mathrm{RCT}$ )을 활용한 영향평가(impact evaluation)의 기법을 적극적으로 도입하고 있다. 최근 들불처 럼 번지고 있는 영향평가(impact evaluation)는 윌리엄 이스털리(William R. Easterly)의 말처 럼 '개발신화에 대한 대안(Easterly, 2011: 53)'으로 각광받고 있다.

$\mathrm{OECD}$ 의 개발원조위원회(DAC)는 2009년부터 2012년까지 실시된 DAC 동료검토(peer review)의 결과를 기초로 개발평가에 대한 12 가지 중요한 교훈을 담은 '개발활동의 평가 (evaluating development activities)'에서 “성과에 대한 올바르지 못한 이해는 목표설정에 실패 하며 원조효과를 떨어뜨려 원조 품질을 저하시킬 수 있다. 이는 금전적인 손해일 뿐 아니라, 빈곤 과 소외로 인해 고통 받으며 원조가 절실한 전 세계 사람들의 생명과 생계수단을 잃을 수 있는 문제가 된다(OECD, 2013: 12)”라고 하면서 원조의 품질을 제고하기 위해서는 사업의 성과관리 가 필요하다는 것을 지적하고 있다.

그러나 통계의 기초가 되는 개발도상국 사업현장에서의 데이터(data)의 부실·부족과 '거미의 역 설(micro-macro paradox)'(Mosely, 1986: 22-7)1)은 여전히 개발원조의 현장을 안개처럼 시 야를 가리고 있는 상황이다. 특히 개발도상국의 개발 현장에서 개발원조 활동을 기획·집행·모니 터링 및 평가(Monitoring \& Evaluation, M\&E)를 시행함에 있어 당초 목적에 대비한 성과를 거 두고 있는지 여부에 대하여 일관성 있게 관리·감독할 수 있는 수단이 미흡하거나, 적합한 방법을 개발행정에 적용하지 못하고 있는 실정이다. 예컨대 영향평가는 이스털리(William R. Easterly) 의 말대로 '기존방식의 원조로 하지 말아야 할 것이 무엇인지'(Easterly, 2011:53; KOICA ODA 교육원, 2012: 252)만을 알려주는데 그칠 수 있고, 협소한 범위의 지표에 집중하도록 하여 역량 측정이 어렵기 때문이다(Sida, 2014: 52). 영향평가로부터 나온 결과가 있다 하더라도 여전히 사 업이 진행되고 있는 현장에서 시간, 인력 등 공정과 위험 등을 관리하기 위한 관리도구의 필요성 은 여전히 남아있다.

본고에서는 근래 강조되어 오고 있는 역량개발 지원을 위한 개발원조 사업을 보다 체계적이고 일관성 있게 성과를 관리하기 위한 방안으로서 개별 사업에 적용할 수 있는 모델과 프레임워크의 운영을 제안하고 있다. 특히 대한민국 감사원이 수행하고 있는 '베트남 감사원 역량강화 지원사업'

1) 공여국 개개의 개발협력사업은 성공하였으나, 그 개발사업을 통해 얻으려는 수원국 국가차원의 목적달성에는 기여하지 못했다는 연구결과를 의미하는 바, 원조의 용도대체(aid fungibility)를 설명하는 하나의 원인으로 들고 있다.

(출처: KOICA ODA 교육원, "국제개발의 첫걸음』; 조광걸, 국제개발협력의 주요이슈, p.235; Mosley, P, 1986, "AidEffectiveness: The Micro-Macro Paradox”. IDS Bulletin vol. 17:22-7 재인용) 
에 적용하여 일정한 성과를 거둔 사례 결과물인 '다년도 역량개발 모델(MCM) 및 단계별 성과관 리 프레임워크(PPMf)'를 소개하고자 한다. 나아가 해당 '다년도 성과관리를 위한 모델 및 프레임 워크'를 여타 개발원조 사업에도 적용함으로써 $\mathrm{KOICA}$ 의 개발 행정상 효율성을 제고하고, 폭증하 는 사업 량을 효과적으로 관리하며, 나아가 사업의 품질을 제고할 수 있는 사업관리 도구로서 활 용할 것을 제안하고 있다.

\section{II. 역량개발과 제도개선2)}

\section{1. 역량개발과 제도개선의 필요성}

최근 국제사회는 개도국으로 하여금 잠재력을 발휘하여 자생력을 키우고 주인의식을 갖도록 한 다는 취지에서 역량개발 (capacity development)에 역점을 두고 있다. 세계은행(World Bank)은 세계 개발원조 금액의 약 $25 \%$ 가 역량개발에 투입되고 있다고 추산하고 있다. 역량개발(capacity development)은 기존 '자원의 단순 이전(simply resource transfer)'에서부터 개도국의 잠재력 을 발휘하도록 한다는 면에서 국제 개발원조에 있어 인식체계의 대전환(paradigm shift)을 이루 어왔다(Land et al., 2015).3)

〈박스 1〉 개인성과를 넘어 조직차원의 성과가 필요한 이유

세계은행은 아프리카 말리(Mali)의 경우 보건문제 해결을 위해 개인과 조직의 역량강화를 위해 노력했으나, 직원들의 취약한 보수로 인해 소기의 목적을 달성하지 못했으며, 개인들의 경우 필요이상의 훈련을 받는 반면, 훈련 성과를 잘 활용할 수 있는 제도개선이 없어 실패했다는 사례를 소개하고 있다. 좋은 교육을 받은 우수한 인재가 자국을 떠나 선 진국으로 유입되는 두뇌유출(brain drain)을 유발하여 결국 수원국의 역량이 약화되는 상황을 목도하고 있는 것이다 (Thomas, 2006: 2).이러한 상황은 특히 전문성을 갖고 있는 감사부문의 경우에도 적용되며, 유능한 직원을 회계사 등 사적부문으로 전직하는 결과를 초래할 수 있어 보수 등을 포함한 인사체제의 변화도 고려할 필요가 있다.

출처: 조광걸 (2015), Hegarty, A and Musonda. K. (2012) 재인용

2) 역량강화(capacity building)와 달리 역량개발(capacity development)의 개념은 개인의 능력향상을 넘어 조직, 제도 차원 의 개선을 포함하고 있으나, 실제 사업명칭 등에서 이를 혼용하고 있는 현실을 고려하여(예, "베트남 감사원 역량강화 지 원사업(2014 2016)') 제도개선을 역량개발과 구분하여 부제함. (출처: KOICA, 2012, "국제사회의 역량개발 지원정책". p.9 15) (본문의 이하 내용 중 일부는 대한민국 감사원이 수행하고 있는 '베트남 감사원 역량강화 지원사업'의 사례를 토대로 연구한『개발도상국 감사원 역량강화 지원방안 연구』보고서(2015)에 기초하여 재작성되었다.)

3) 그러나 '역량개발은 새로운 개념이 아니라 1960,70 년대 다양한 개발논의에 뿌리를 두고 있으며, 탈식민지화 기간에는 신생독립국들의 자결(self-determination), 정치 행정 체제의 수립 등 국가재건을 위한 개인, 조직, 제도 전반에 걸친 활동 으로 다양한 학문과 경험을 통해 개념과 접근방법이 진화되어 왔다.'는 의견이 있다. 
그러나 아쉬운 점은 기존 공여국들은 역량강화 문제를 해결하기 위하여 개인 훈련비용을 지원 하고, 훈련생 수로서 그 성과를 측정하고는 했었다는 것이다. 그 결과 좋은 교육을 받은 우수한 인재가 자국을 떠나 선진국으로 유입되는 두뇌유출(brain drain)을 초래함으로써 수원국의 역량 이 약화되는 결과를 목도하고 있다. 이러한 상황은 특히 전문성을 갖고 있는 의사, 간호사, 회계 사, 감사 등 전문직의 경우에 심하므로 수원국 정부의 역량확충을 위해서는 정부기관의 보수, 인 사 체제의 변화도 고려해야 한다. 이처럼 개도국의 역량강화를 위해서는 개인의 역량강화가 조직 의 역량강화에 연계되어야 하고, 나아가 제도상의 변화를 이끌어 낼 수 있어야 한다는 주장이 보 편화되고 있다. 역량개발의 효과를 위해 중요하게 고려되어야 할 사항은 개인의 성과는 물론, 조 직의 지속적인 혁신과 제도상 게임의 법칙이 어떻게 잘 연계되어 있느냐라는 것이다. 세계은행은 다음에 살펴보는 바와 같이 개인의 역량강화는 물론, 이를 넘어 조직의 역량강화와 나아가 제도 개선으로 이어지는 상호 연계성에 주목하고 있다(Thomas, V., 2006: 5).

제 I 장

제 II 장

제 III장

\section{2. 세계은행의 역량개발 모델}

세계은행은 역량개발 사업을 실제 추진함에 있어 사업모형의 부재로 인하여 사업 수요와 활동 및 결과간의 연결고리(수요파악, 역량개발 활동, 성과)가 취약하게 된 결과를 초래하였다고 밝히 고 있다. 나아가 역량개발에 대한 수혜국과 공여국간의 공통인식의 부족을 야기하고, 현지에 대한 이해부족(현지 관행 및 지식, 현지 사회정치 요소, 정책 등 역량개발에 영향을 미치는 요인)을 방 치하는 상황을 야기하고 있다고 지적하고 있다. 이에 따라 세계은행은 일반적인 역량개발 모형 (〈박스 2〉)을 수립하고 그 활용을 장려하고 있다 (KOICA, 2015: 60; Otoo. S. et al., 2009: 19). 이러한 역량개발 모형의 활용 이점은 역량개발을 위한 개별 활동이 어떻게 성과와 목적 달 성에 이바지하는지 파악할 수 있고, 나아가 변화를 주도하는 사람/그룹(change agent)이 개발사 업의 목적달성에 우호적인 변화를 이끌어낼 수 있도록 집중하게 한다는 것이다. 세계은행의 역량 개발 모형에 따르면, '개발목표를 달성하기 위한 역량개발(Capacity for Achieving a Development Goal)'을 위해서는 연수를 통한 학습활동을 넘어 조직 내에 제도적 변화를 이룰 수 있는 변화과정 이 필요하다는 것이다. 이를 위해서는 변화를 주도할 수 있는 개인이나 그룹(change agent)의 역할이 필수적이다 (Hegarty. A, and Musonda. K., 2012: 12).4)

4) $\mathrm{OECD}$ 는 감사원의 역량개발의 경우 주요한 관리 측면을 '개인의 감사 전문성', '조직의 역량', '국회, 언론 등 외부환경 관 리역량'으로 3분하고 있다. (출처: Hegarty. A, and Musonda. K. 2012, p.12) 


\section{〈박스 2〉세계은행의 역량개발 모형}

세계은행(World Bank)의 역량개발 성과 프레임워크에 따르면, 개도국 공무원들은 연수를 통해 아래 그림과 같이 크 게 여섯 가지 초기 학습 결과(initial learning outcome)를 습득한다. 이러한 학습 결과는 연수생이 변화의 주도자 (change agent)로서 이해관계자 및 리더의 인식을 제고하여 변화를 가능케 하는 사회정치적 환경을 조성하고, 관련 정책과 전략을 수립하며, 조직 운영을 개선함으로써 개발 목표를 달성할 수 있도록 하는 역할을 수행해야 함을 의미한 다.

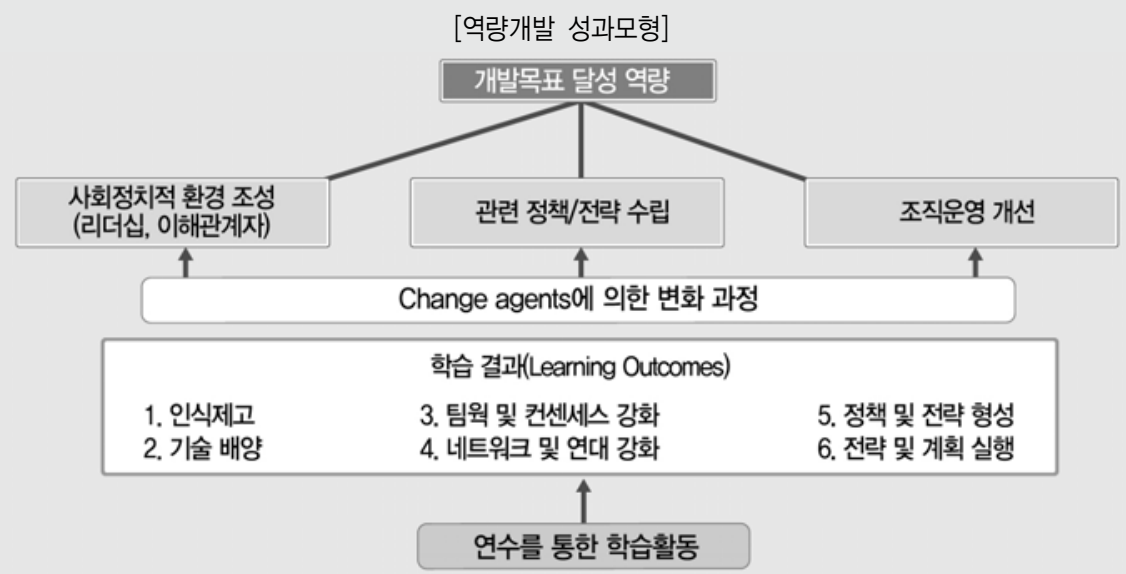

출처: 세계은행 (2009)

상기 세계은행의 성과모형은 개별 활동과 목적과의 연계를 강화하고 있다는 점과 아울러 성과 달성을 위해서 특별히 주목해야할 요소를 발굴한다는 점에서 의미가 있다. 또한, 일련의 활동에 대한 논리적 과정을 파악할 수 있도록 하고 있다. 그러나 실제 개발원조의 사업현장에서 각각의 역량개발 사업의 성과관리를 할 수 있는 관리도구로서 기능할 수 있을는지 의문이다. 왜냐하면 이를 실제 활용하기 위해서는 보다 구체적인 사업 내용이 담겨야 하고, 프레임워크와 연계시킬 수 있는 연결고리가 필요하기 때문이다.

\section{3. 스웨덴 국제개발협력청(Sida)의 역량개발 평가 결과}

스웨덴 국제개발협력청(Sida)는 최근 스웨덴 등 북구 3 개국의 역량개발 사업의 결과를 평가하 면서 변화이론(Theory of Change, ToC)을 응용한 분석모델을 수립하고, 이에 기초하여 평가를 시행한 바 있다. 이에 따르면 동 분석모델은 논리적 연결고리를 다음과 같이 '역량개발 투입 $\rightarrow$ 역량개발 진행 $\rightarrow$ 역량개발 증진 $\rightarrow$ 실적/산출물 제고 $\rightarrow$ 성과(outcome) 제고 $\rightarrow$ 최종성과물 (impact) 제고’로 설정하고 있다. 


\section{〈그림 1〉역량개발 지원사업의 변화이론}

(A generic theory of change of donor support to capacity development)

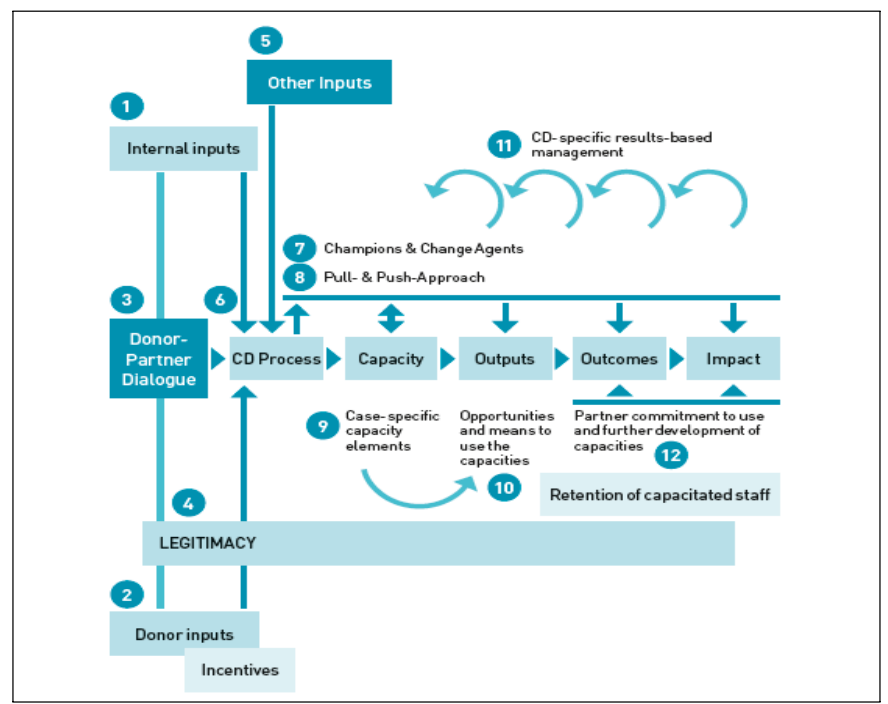

출처: Sida (2015) p.121

동 연구는 UNDP 연구 등을 반영한 역량개발을 위한 변화이론의 가설로서 다음과 같이 요약할 수 있다. '역량개발은 대체로 내부적 과정이며, 현지 이해관계자가 주도할 때 역량강화 지원은 성 공 가능성이 높고, 변화에 유연해야하며, 역량강화에 미치는 요소가 다양하므로 외부지원은 역량 강화에 기여(contribute)할 수 있을 뿐이다. 또한, 조직상 측정 가능한 변화를 야기하는데 집중하 는 것이 유용하며, 훈련, 기술원조, 지식전수 등 외부로부터의 지원은 품질이 중요하지만 그 효과 성은 수원국 측의 수요가 얼마나 절실한지에 달려있다(Sida, 2015: 157-8). ${ }^{5}$ ) 동 평가보고서는 상기 가설내용의 유효성 외에도 공여국의 지원역량에 대한 사전 점검, 양국간 긴밀한 대화의 필 요성, 역량강화 사업의 정당성 유지 등을 역량강화 사업의 성공 요소로 밝히고 있다. 동 보고서가 밝히고 있는 일반적인 성공 요인〈박스 3〉은 향후 개별적인 역량개발 사업을 기획/수행함에 있어 반영할 필요가 있다.

〈그림 1〉 '역량개발 지원사업의 변화이론'의 모델은 사업수행 모델이 아니라 평가분석 모델로서 연수생들이 어떻게 자신들의 역량을 활용하는지에 관한 논리로서 변화이론에 반영하고 있으며, 실제 사업의 실행단계에서는 산출물(output)이 당초 목표한 개인 혹은 조직의 역량 변화에 기여

5) 동 연구는 Sida, Danida, Norad등 북구3국의 역량개발 사업에 대한 연구로서 2014.9 2015.6월간 29건의 사업기획서, 13 건의 심층 기획과정 검토 및 3 건의 국별 사례 조사를 통하여 추진되었다. 동 연구물은 2015.8월 발표에 이어 하반기 에 발간된 것으로 보여 '베트남 감사원 역량강화 지원사업’의 MCM과 PPMf 적용과 유사한 시기에 추진된 것으로 보인다. (출처: Sida. 2015. "Support to Capacity Development - Identifying Good Practice in Swedish Development Cooperation”. pp157 158) 
하지 못한 것으로 파악하고 있다(Sida, 2015: 122). 따라서 사업 기획/실행단계에서 산출물 (output)은 지정할 수 있을 지라도, 성과물(outcome)이나 최종 성과물(impact)은 사업의 지향하 는 목표들(goals)로 표현하는 것이 보다 현실적이며 사업이후에 성과물 혹은최종 성과물로서 평 가하는 것이 바람직하다고 본다. 이점에서 III항에서 살펴볼 '다년간 역량개발 모델(MCM)'과 다르 며 사업 실행에서 출발한 것이 아닌 까닭에 사업의 '단계별 성과관리 툴(PPMf)'이 개발되거나 이 와 연계되지 않은 것으로 보인다.

\section{〈박스 3〉 Sida 역량개발사업의 모범사례의 주요 성공요인}

(1) 수원국의 정책, 전략과 우선순위가 파악되어야 하고, 수원국 기여와 관리능력이 확인되어야 한다.

(2) 공여국은 지원약속이전에 역량개발과정을 관리하고 지원할 역량이 있는 지 사전 평가할 필요가 있다.

(3) 사전 준비단계에서 공여국 및 수원국간의 대화는 i) 직원인센티브, 관리전통, 엘리트의 이해관계 등 예민한 문제, ii) 공동 역량수요 조사, iii) 목적 및 기대효과 합의, iv) 역량개발 목표치의 복잡성에 관한 모든 관여자들의 필요한 노력 조사 등을 아울러야 한다.

(4) 역량강화 사업의 당위성은 양국간 초기 상호관계 설정을 통해 형성되며, 양자간 관계에 따라 강화되거나 약화된다.

(5) 수원기관 외에 개인들로부터의 투입을 사업에 반영하여야 하며, 이는 역량 개발의 변화과정을 지속하는데 도움이 될 수 있다.

(6) 역량개발 과정은 사업별로 기획되어야 하는바, i) 포괄적인 수요 및 맥락분석을 반영하여야 하고, ii) 변화에 수용적이어야 하며, iii) 내부 혁신과정과 연계되어야 하며, iv) 수원기관의 일상적인 절차에 포함되어야 하며, v) 수원기관의 변화과정의 관리능력 강화를 고려하여야 한다.

(7) 변화과정을 지원할 수 있고 저항을 극복할 수 있는 주요인물 들을 사업기간 중(내내) 활용하고, 그 장점을 건별로 평가할 필요가 있다.

(8) 수원기관 및 외부 주요인물의 장점과 요건은 수요공급 양측면에서 건별로 고려되어야 하며, 외부 주요인물의 관여에 따라 공여국 개입의 당위성과 관계가 영향을 받을 수 있다.

(9) 어떠한 역량을 개발할 것인지에 대한 결정은 현재 및 필요 역량에 대한 평가를 통해 이뤄지며, 통합적 역량개발과정차원에서 서로 다른 역량간의 상호의존성을 고려해야 한다.

(10) 수원기관에서 활용될 새로운 역량의 기회와 방법들이 현존 절차와 통합될 수 있도록 확인할 필요가 있다.

(11) 역량개발 결과에 집중하고 활동을 조율하며 성취의 정도에 대한 공통된 이해를 촉진하기 위하여 역량개발 과정 및 결과에 대하여 점검평가하고, 보고할 필요가 있다.

(12) 수원국은 공여국의 지원종료 후에도 역량개발 과정을 지속한다는 약속을 할 필요가 있으며, 출구전략은 양국이 공동으로 기획해야 한다.

출처: Sida (2015) p.22-5

\section{4. 세계최고감사기구 개발 이니셔티브(IDI)의 감사 역량개발사업 평가}

세계 각국의 감사원을 회원으로 하는 세계최고감사기구(INTOSAI6))는 그 산하에 감사원간 특 히, 개도국과 선진 공여국간의 감사 역량개발 사업을 촉진하기 위한 개발이니셔티브(INTOSAI Developemt Initiative, IDI)가 설치되어있다. IDI는 최근 19 건의 역량개발사업의 평가보고서에 대한 메타분석을 시행하고 $\mathrm{OECD} / \mathrm{DAC}$ 의 5 대 평가항목에 따라 역량개발사업에 대한 평가결과와

6) INTOSAI(International Supreme Audit Institute)는 1953년에 설립, 현재 회원국은 195개국이다. (출처: 저자작성) 
권고 의견을 제시하고 있다(Pot, 2014).

이에 따르면, 기술적 차원의 지원은 역설적이게도 태도나 제도를 개선하는 변화를 촉발하기보다 때로는 비생산적일 수 있으므로 인센티브, 조직의 제도와 문화의 변화를 함께 고려해야 한다는 것이다. 또한, 제도와 관행상에 변화를 가져올 수 있는 첫 단계는 먼저 감사원 고위 경영진을 설득 하여 효과적인 선례가 전수될 수 있도록 환경을 조성해야 한다는 것이다. 또한 성과 목표를 지정 함에 있어 수혜 감사기구의 능력 범위 내에 있는 구체적인 것을 지정해야 하며, 대등한 파트너십에 기초할 것을 강조하고 있다(IDI, 2014, 16 18쪽). 특히, '개혁의 최적인물(reform champion)' 을 지정하는 것이 중요하며, 너무 바쁘거나 정치적인 고위급을 지정할 필요는 없고 중간단위 이 상의 직원으로서 사업관리가 가능한 직원이면 바람직하다고 한다(IDI, 2014, p20, 29). 또한, 다 양한 사업수단(장기 혹은 단기 자문관, 강의실 강의 혹은 현장 학습, 자문 지원 혹은 제도 이식 (twinning7)) 등)(Hegarty and Musonda, 2012: 69)을 적절히 혼용할 것을 권고하고 있다. 특 히, 성과제고를 위해서는 연수생들의 태도(attitude)에 영항을 미칠 수 있어야 하며, 이를 위해 제도 및 조직 문화, 진실성, 동기부여 촉진 등에 집중할 수 있는 변화관리 수단을 명시적으로 활 용해야 한다고 하고 있다(IDI, 2014: 31).

\section{KOICA 우수사례 분석 및 시사점}

$\mathrm{KOICA}$ 의 다년간 연수사업은 도입한 지 3 년 정도 경과한 초기 사업 형태이며 사업의 효과를 확 보하기 위해 지속적으로 진화하고 있다. 2014년에는 다년간 연수사업 중 우수사례를 선정하여 성 과사례집을 발간하여 연수기관들이 참고하도록 하고 있다(KOICA, 2014).8) 우수 성과사례로 선정 된 5 개 사업 중 2 개 사업에 특히 집중한 바, 국가기록원 및 연세대학교 간호 대학원을 대상으로 심층 면담을 통한 사례 분석을 실시하였다. ${ }^{9)}$ 그 결과 국가기록원, 연세대 간호대학원은 공히 핵심 요원(key person)을 지정하여 연수생 스스로 실행계획을 도출하도록 코칭(coaching)하는 역할을 수행하였고, 연수생들이 본국에 귀국한 이후에도 지속적으로 자문을 제공한 것으로 파악되었다.

7) 인도네시아는 세계은행과 아시아개발은행뿐 아니라 13 개 선진 SAl 회원국으로부터 양자협력을 받고 있는 바, 공여국이 제도적 지원과 훈련 및 자문을 통해 장기적 협력을 할 경우 '특정분야에 대한' 제도이식이 도움이 되었다고 밝히고 있다. (출처: Anthony Hegarty \& Kennedy Musonda(2012), Good Practices in Supporting Supreme Audit Institutions, OECD, p. 69.)

8) KOICA, 연수사업 성과사례집(2014)에는 다년간 연수사업으로서 국별 연수 3개 사업(몽골 1건은 2014년 단년도 사업), 다국가 연수 5 개 사업이 실려 있다. (출처: 저자작성)

9) 이들 두 기관의 선정과 관련하여, 연세대학교 간호대학원은 교육기관이고, 국가기록원의 경우 일반 행정기능을 수행하고 있다. 아울러 이들 기관의 참가 연수생들은 이전부터 한국 측과 지속적으로 긴밀한 유대관계를 형성하여 왔고, 대부분 동일한 업역에 종사하고 있었다. 이들 연수기관은 공히 업무 매뉴얼 작성을 실행계획으로 선정하여 소기의 성과를 거두 었다는 점에서 제도상 역량강화 측면에서 시사하는 바가 적지 않다. (출처: 저자작성) 
우수 사례 기관의 담당자 면담과 함께 상기 ' $\mathrm{KOICA}$ 우수사례집' 등 문헌 검토와 $\mathrm{KOICA}$ 실무 진과의 실무회의 결과에 따르면 몇 가지 의미있는 사실이 발견되었다. 즉, 실행계획은 보다 구체 적이고 집행 가능하도록 그 범위를 좁혀 수립할 필요가 있으며, 연수효과의 수원국 내 파급과 실 행계획의 시행을 위해서는 핵심요원(key person)을 지정, 운영하는 것이 효과적이라는 공통된 사 실을 발견할 수 있었다. 또한 핵심요원은 해당 조직 내 영향력이 있는 직책을 가진 책임성 있고 의욕있는 사람이어야 하며, 지속가능한 협력과 참여적 성과관리를 위해 계속 연수과정에 참여할 수 있어야 한다는 것이다. 이러한 내용은 IDI의 평가 보고서에서 권고하고 있는 내용과 일맥상통 하는 것이었다.

〈표 1〉 KOICA 다년도 연수사업 중 우수사례 분석결과

\begin{tabular}{|c|c|c|}
\hline 구분 & 국가기록원 & 연세대 간호대학원 \\
\hline $\begin{array}{l}\text { 사업 } \\
\text { 개요 }\end{array}$ & $\begin{array}{l}\text { - 사업기간: 2013 2015 } \\
\text { - 대상국가: 캄보디아, 베트남 등 아시아 5개국 } \\
\text { - 사업내용: 자료보존 및 디지털화 }\end{array}$ & $\begin{array}{l}\text { - 사업기간: 2012 2014 } \\
\text { - 대상국가: 에티오피아등 아프리카 3개국 } \\
\text { - 사업내용: 간호 표준교육과정 및 매뉴얼 개발 }\end{array}$ \\
\hline $\begin{array}{l}\text { 차별화된 } \\
\text { 성과 }\end{array}$ & $\begin{array}{l}\text { - 국제표준에 따라 기록물관리 및 보존 가능 시스템 } \\
\text { 구축 }\end{array}$ & - 간호교육 표준화 및 매뉴얼 개발, 전국 보급 \\
\hline $\begin{array}{l}\text { 성공 } \\
\text { 요인 }\end{array}$ & $\begin{array}{l}\text { - 양 기관간 기 구축 네트워크로 신뢰 관계 형성으로 } \\
\text { 문제점 적극 노출, 협의 } \\
\text { - 연수기관 차원의 자문 등 별도 지원과 적극적 과정 } \\
\text { 운영 }\end{array}$ & $\begin{array}{l}\text { - key person이 3개년 계속 참여하여 연차별 } \\
\text { 사업연계 가능. } \\
\text { - 온라인 코칭, 자문 등 연수기관의 지속적인 지원 }\end{array}$ \\
\hline
\end{tabular}

출처: 조광걸 (2015) p.64

\section{KOICA 역량개발 지원사업의 모델}

\section{1. 다년도 역량개발 모델 (MCM)}

개발원조사업의 성과관리를 위해서는 해당 사업이 추구하고 있는 목적을 효과적이고 효율적으 로 달성하기 위한 실천적 모델을 수립할 필요가 있다. 아울러 이러한 목적 달성을 위해 동원하는 다양한 수단들과 위험요인들을 효과적으로 관리해야 할 프레임워크 역시 필요하다. 개별사업에 부합하는 적정한 성과관리 프레임워크가 없으면, 개발 수요와 활동 및 결과 간의 연결고리(수요파 악, 역량개발 활동, 성과)가 취약하여 소기의 성과를 얻기 어렵다는 것이 세계은행(World Bank) 의 연구결과이다(Otto et al., 2009: 2). 또한 IDI는 회원국들의 감사 역량개발 보고서 19 건에 대한 메타분석을 통하여 해당 평가의 절반 정도만이 사업수행을 위한 모니터링 프레임워크 문제 
를 다루었다면서, 감사부문 역량개발의 성과를 측정하는 것이 매우 어렵고, 성과의 지속가능성에 관해서는 거의 다루지 못하고 있는 실정이라고 소개하고 있다(Pot, 2014: 15).

$\mathrm{KOICA}$ 는 세계은행(World Bank)의 연구와 국제 경향에 부합하여 기존 다국가-일회성 연수사 업의 형식에 기초하여 연수생 개인의 역량강화에 초점을 맞춰온 기존의 단년도 연수사업을 점차 축소하고, 다년간 연수사업을 도입하여 확대 운영 중에 있다(KOICA, 2015: 54).10) 다년간 연수 사업은 KOICA가 연수생 개인의 성과를 넘어 조직차원의 역량강화를 목적(goal)으로 하는 새로운 형태의 사업이라 할 것이다. 금번 '베트남 감사원 역량강화 지원사업 역시 베트남 측이 우리나라 의 감사경험과 기법을 학습할 뿐 아니라, 나아가 그들이 안고 있는 주요 과제를 해결하고, 혁신 내용을 제도화함으로써 개인과 조직의 역량을 함께 강화해 나갈 수 있는 지원(支援) 전략과 체계 적인 수단을 필요로 하였다. 이처럼 다년간에 걸쳐 역량개발을 지원하는 경우에는 시간의 경과와 담당자의 교체에도 불구하고 일관성 있고 체계적으로 사업을 관리할 필요가 있다. 역량개발 (capacity development)이라 함은 "개인차원에서 지식의 전수(transfer of knowledge)를 넘어 조직 및 사회 차원에서 개도국 스스로의 개발과제 대처능력을 제고하는 과정(process)을 의미" (KOICA, 2012: 9)하기 때문이며, 이러한 능력제고 과정을 담아낼 수 있는 사업관리 모델과 프 레임워크가 필요한 것이다.

〈그림 2〉다년도 역량강화 모델(MCM)의 기본원리

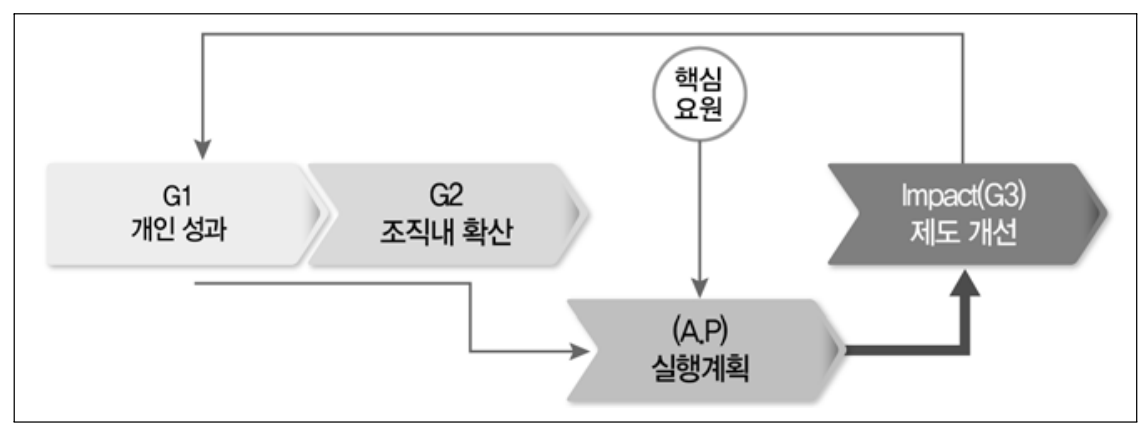

출처: 저자작성

〈그림 2〉에서 보는 바와 같이 '다년도 역량개발 모델(Multi-year Capacity-development Model, $\mathrm{MCM}$ '은 총 3 단계(개인성과, 조직 내 확산, 제도개선)으로 구성되어 있다. 이들 3 단계 구성요소들은 사실상 단계별 사업 목적이며, 단계별 목적은 차 상위 목적달성에 기여하도록 구성 되어 있다. ${ }^{11)}$ 즉 연수를 통해 개인의 역량강화라는 개인적 성과가 달성될 수 있도록 구성되어야

10) 단년도 연수의 경우 제한된 예산에서 친한인사 양성이라는 측면이 강조되어 개인 역량강화와 만족도가 주된 목표를 이 루고 있다. (출처: KOICA. 2015. 『글로벌연수 길라잡이』, p.54.) 
하며, 이어서 연수생 개인이 거둔 연수 성과를 조직 내에서 공유하고 조직원간에 학습을 촉진할 수 있어야 한다. 나아가 연수생들이 연수과정에서 수립한 실행계획(action plan)을 통해 조직 내 의 문제를 해결하고 혁신적 사항을 제도화하는 것이 필요하다. 이러한 일련의 활동들은 추진 과 정상 지속적인 환류(feedback)를 통해 개인의 성과를 제고시키고 나아가 제도상의 혁신을 이뤄나 가는 것이다.

이처럼 단순명확한 사업모델을 통하여 개발도상국 관계자들이 사업의 논리와 성과를 쉽게 이 해하고 공통의 목적의식을 가질 수 있다는 것은 매우 의미가 크다 하겠다. 참고로 핵심요원(key person)12)의 중요성은 세계은행은 물론 IDI의 연구결과에서 검증된 사안이며, $\mathrm{KOICA}$ 의 우수사 례로서 추천된 국가기록원 및 연세대학교 보건대학원의 담당자, $\mathrm{KOICA}$ 담당자와의 인터뷰에서 재차 확인된 사항이다.

\section{2. 단계별 성과관리 프레임워크(PPMf)}

역량개발 지원사업의 단계별 목적을 달성하기 위해서는 구체적인 성과관리 수단으로서의 사업 모델과 부합한 사업관리 프레임워크가 있어야 그 목적 실현을 용이하게 관리할 수 있을 것이다. 이러한 기능을 충실히 이행할 수 있는 사업관리 프레임워크는 각종 투입물 및 산출물 관리, 그리 고 소기의 성과를 확보하기 위한 성과관리 수단을 세분화하고, 이들의 연관관계를 명확히 알 수 있게 함으로써 보다 효과적인 사업관리를 가능하게 해야 한다. 특히 개발사업의 관리에 있어 보다 일관성 있고 결과에 기반한(result-based)의 성과관리에 도움을 줄 수 있어야 한다. 특히, 성과 물을 확보하기 위해서는 수원국측의 협력은 결정적이다. 수원국의 주인의식(ownership) 내재화 와 이를 토대로 한 지속적인 역량개발을 위해서는 공여국의 지원활동 외에 수원국 자신들의 혁신 적 노력이 필요하기 때문이다. '역량개발은 내재적 과정으로서 공여국은 이에 기여(contribution) 할 수 있을 뿐이며, 그 결과에 대해 귀속(attribution)됨을 주장할 수 없다'(Sida, 2015: 151)할 것이다. 사업관리 프레임워크는 조직차원의 역량을 강화하기 위한 목적을 달성하기 위해 수원국 과 공여국의 상호 역할분담과 협력, 이에 관한 공통의 인식을 담아낼 수 있어야 한다.

위와 같은 요건을 충족할 수 있는 '단계별 성과관리 프레임워크(Phased Performance Management framework, PPMf)'의 작성은 〈그림 3〉에서 보는 바와 같이 먼저 총 사업기간을 세로로, 사업 활동과 성과물을 가로로 매트릭스를 구성하고, 연차별로 투입물-산출물-성과물 및 위험관리를

11) 본고에서는 기획단계에서는 사업의 목적(goal)로, 사업의 점검 및 평가(M\&E) 단계에서는 이를 성과물(outcome) 및 최종 성과물(impact)로 표현하고 있다.

12) 세계은행의 change agent(변화의 주도자), IDI의 reform champion(혁신 최적자)을 KOICA와 본서에서는 핵심요인(key person)이라고 칭하고 있다. 
기입하도록 하고 있다. 이렇게 하면 해당 사업의 전체 투입물, 산출물, 성과관리 지표 및 위험관리 요소 등을 한눈에 볼 수 있다. 또한, 최종 성과에 이르기 위하여 매년도 성과관리 지표(indicator) 를 통해 성과 목표(target)를 정함으로써 해당 사업의 목적(goal)을 달성하는 데 징검다리 역할을 할 것이다. 기획단계에서의 사업의 목적(goal)은 단계별 활동 종료 후 성과물(outcome)로 점검하 고 평가할 수 있다. 목적(goal) 대비 실제 성과물(outcome)을 상호 대비할 수도 있을 것이다. 대 개 개발에 있어 최종 성과물(impact)을 얻기 위해서는 다소의 시간이 소요되므로 '사업종료 후 평 가'에서 측정하기도 한다.

$\mathrm{PPMf}$ 를 활용함으로써 단계별 혹은 시기별 목적(goal 1, goal 2)과 최종 성과물(impact)간의 연계를 명시적으로 함으로써 최종 성과를 달성하기 위한 사업관리에 일관성(consistency)을 높일 수 있다. 만일 사업 기간을 연장하거나 사업의 규모를 확대할 필요가 있을 경우에는 기간/단계별 로 확장하여 관리를 연장할 수 있다. 특히 사업 내용상 변경이 발생할 경우에도 이전 단계 사업 과 비교하여 성과관리를 할 수 있는 것이다.

최종 성과물(impact)은 수원국의 협력이 필요한 사항으로서 공여국의 일방적인 관리대상이라 고 보기에는 사실상 어렵다. 개발협력은 본질적으로 협상과정을 통해 형성되고 추진되기 때문이 다. 해당 사업의 성격과 성과물 등을 고려하여 공여국과 수원국이 적절히 역할분담을 하는 것이 필요하다. 이러한 접근은 수원국으로 하여금 뚜렷한 주인의식(ownership)과 명확한 목표의식을 갖도록 함으로써 개발사업의 효과성 제고에 기여할 것이다.

〈그림 3〉 단계별 성과관리프레임워크(PPMf)의 작성원리

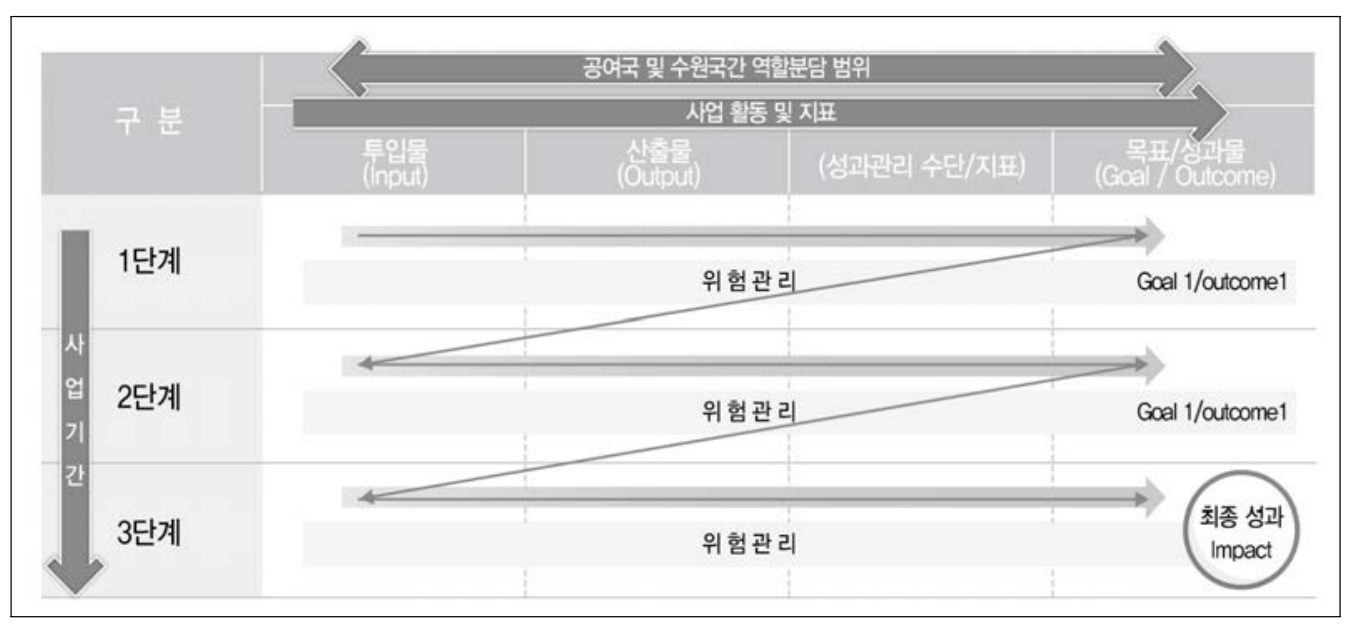

출처: 저자작성 


\section{3. $\mathrm{MCM}$ 과 PPMf 관계 및 기타 활용}

상기 '단계별 성과관리 프레임워크(Phased Performance Management framework, PPMf)' 는 사업모델인 '다년도 역량개발 모델(Multi-year Capacity-development Model, MCM)'의 각 단계별 내용인 목적(G1, G2, G3)을 프레임워크상의 성과물(G1, G2, G3/ outcome1, outcome2, impact)에 반영하고 있다. ${ }^{13)}$ 또한 $\mathrm{MCM}$ 모델에서 중요히 다루었던 핵심요원(key person)은 $\mathrm{PPMf}$ 프레임워크 내에 성과관리 수단/지표 란에서 중점적으로 점검하도록 하고 있다. 따라서 단 순·명확히 수립했던 단계별 사업목적과 주요 핵심요소가 보다 세부적으로 프레임워크(PPMf)를 통해 발전되어가는 것을 볼 수 있다. 역량개발의 지표(indicator) 설정은 조직 내 정치적 맥락과 주인의식 제고에 기초해야 하고, 단선적 과정이 아니라 위험관리와 정치경제적평가(Political Economy Assessment, PEA)와 연계되어 변화관리에 집중하도록 유의할 필요가 있다(Christopolos, 2014: 4).

한편, $\mathrm{MCM}$ 모델을 통해 사업의 목적과 최종성과물/영향을 누구나 쉽게 논리적으로 이해할 수 있도록 수립하되, $\mathrm{PPMf}$ 를 작성할 때에는 핵심어와 첨부물을 활용하는 것이 바람직할 것이다. 즉 기입할 내용이 많아 질 경우, 예컨대 조달 지연, 예산 집행율의 저조 등 이를 위험관리 차원에서 관리할 필요가 있을 경우에는 핵심어만 PPMf상에 기재하고 세부내용은 첨부함으로써 다양한 사 항을 관리할 수 있을 것이다. (첨부 사례참조)

$\mathrm{KOICA}$ 와 PMC, 연수기관 등 사업집행기관은 해당사업의 '단계별 혹은 시기별 목적'을 어떻게 설정하고, 어떠한 '최종 성과물'을 도출해 나갈 것인가에 관해 집중적인 토론을 갖게 될 것이다. 각 사업별 프레임워크(PPMf)를 연수기관이나 $\mathrm{PMC}$ 등을 통해 작성하도록 하고(특히, 위험요소 등) 이를 통해 다양한 데이터를 기관별 혹은 분야별로 취합·축적하게 되면 사업 형태별·규모별 위 험요소를 유형화 할 수 있을 것이며, 이로써 예기치 못한 위험으로 인한 사업의 실패율을 현격히 낮춰 나갈 수 있을 것이다. 나아가 빅데이터(big data) 등 다양한 데이터 처리방법을 동원하여 사 업의 관리를 향상시킬 수 있을 것으로 보인다.

13) 본고에서는 사업기획·실행단계에서는 사업목적(goal)을, 모니터링 및 평가(M\&E)단계에서는 성과(outcome)로 구별, 대비 하여 성과를 관리하도록 하였다. 


\section{IV. 활용사례 및 확장 모델}

\section{1. 베트남 감사원 역량강화 지원사업 모델 및 프레임워크 운용사례}

상기 '다년도 역량개발 모델(MCM)'과 '단계별 사업관리 프레임워크(PPMf)'를 '베트남 감사원 역량강화 지원사업에 투영시킴으로써 해당 사업을 보다 체계적으로 기획·운영하고 성과관리를 도 모할 수 있었다. 즉, 〈그림 4〉에서 보는 바와 같이 다년도 역량개발 사업 중 2차년도를 맞는 2015년의 경우 ‘연수생 만족도', '연수생 성취도' 등 기존 개인의 성과를 평가할 뿐 아니라, '다년 도 역량개발 모델(MCM)'에 기초하여 조직상의 역량강화를 위한 실행계획(action plan)과 핵심요 원(key person)을 주된 성과관리 항목으로 도출하였고, 지표로 개발해 나갈 수 있었다. 즉, '핵심 요원의 지정', '실행계획의 집중도', '실행계획 참여율' 등 실행계획과 핵심요원을 중심으로 한 평가 지표로 선정할 수 있었다.

제 I 장

제 II 장

제 III 장

평

가

제 $\mathbb{N}$ 장

〈그림 4〉다년도 역량강화 모델과 주요 관리사항

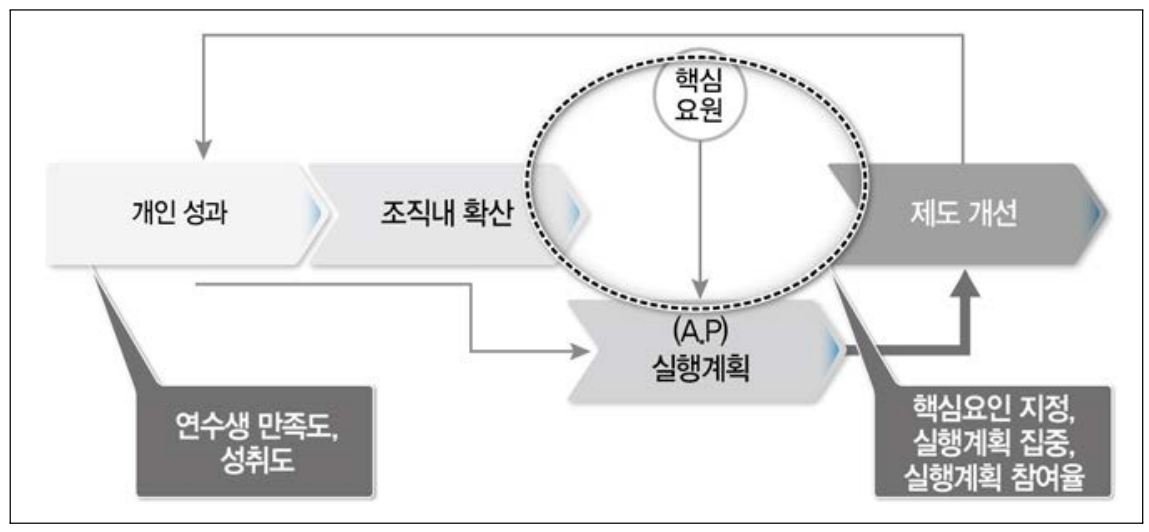

출처: 저자작성

특히 베트남 측과 사업모델(MCM)과 사업관리 툴(PPMf)에 대한 인식을 공유함으로써 베트남 측이 원하는 소기의 성과는 한베 공동의 노력이 있을 때 달성할 수 있는 사안임을 명확히 주지시 킬 수 있었으며, 이로써 베트남 측의 주인의식(ownership)을 제고하고, 보다 허심탄회한 정보공 유는 물론, 베트남 감사원 조직혁신과 실행계획(action plan)과의 연계성을 제고하였고, 핵심요원 의 지정 등을 이끌어낼 수 있었다. 제도개선이라는 상위 목적을 달성하기 위한 성과 지표(핵심요 인의 지정, 실행계획의 집중 등)를 도출하고 이로써 베트남 측과 함께 공통의 성과 지표를 갖게 된 것이다. 


\section{2. 모델의 확장 및 프레임워크}

상기 〈그림 3〉'단계별 성과관리 프레임워크(PPMf)'는 사업기간을 3단계로 한정하고 해당 기간 별로 달성하려는 성과물을 조준하고(targeting) 있다. 그러나 상기 기본적인 모델구성은 사업 단 계에 따라, 혹은 장기간 시간이 소요되는 사업의 시간경과에 따라 사업목적을 확장해 나갈 수 있 다. 즉, 최종성과물을 포괄하는 상위의 성과물을 지정할 경우 차 상위 즉 4,5 단계로 발전해 나갈 수 있는 것이다. 예컨대〈그림 5〉에서와 같이 사회에 대한 영향력(예, 언론의 보도태도 변화, 대 국민 인식변화, 특정사안의 신고 증가 등등)이 궁극의 목적이 될 경우 제도개선 이후 단계로서 해당 목적을 추가하여 단계별 모델이 확장할 수 있을 것이다. 이 경우 그 수단이 KOICA 프로젝트형 사업일 때에는 프로젝트매니저(PM)가 핵심요원에 상당하는 중요한 역할을 담당하게 될 것이다.

〈그림 5〉 다년도 역량개발 모델(MCM)의 확장

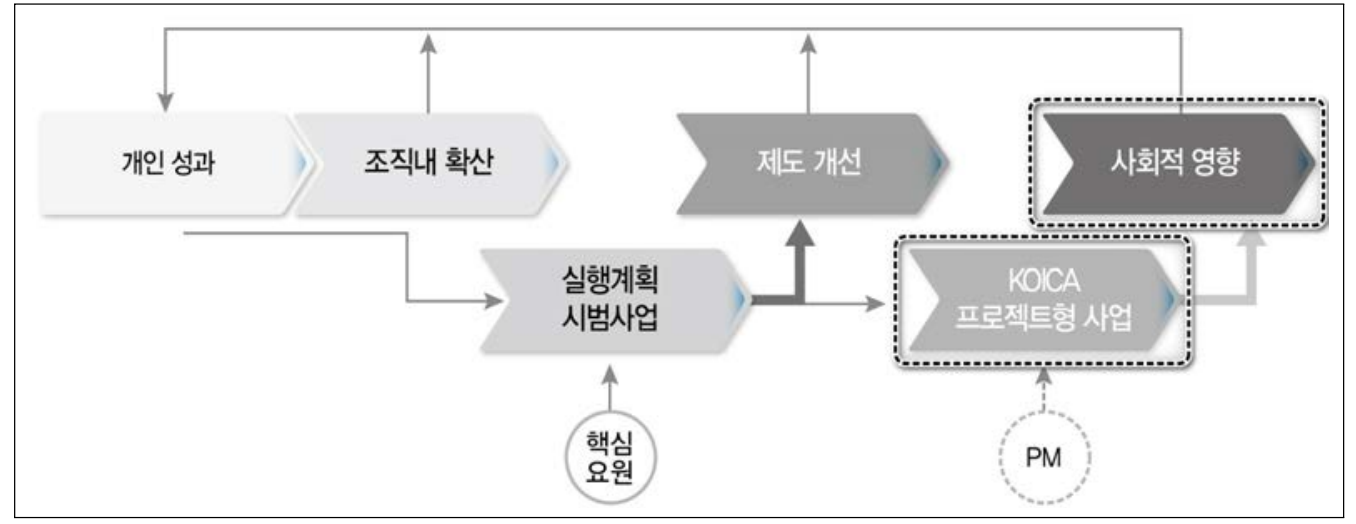

출처: 저자작성

〈그림 3〉 PPMf에서는 이처럼 변화된 성과물의 확장 및 발전과정을 추적할 수 있을 것이며, 이로써 담당자 교체와 시간의 경과에도 불구하고 보다 일관성 있고 통찰력 있는 사업추진을 가능 하게 한다. 또한, PPMf는 위험관리 요소를 외부적 요인14) 외에 투입물과 산출물은 물론, 성과물 과 성과관리 수단 등 사업 활동 내에 존재하는 위험요인을 명시적으로 관리하도록 하고 있다.

\section{3. $\mathrm{PDM}$ 과의 비교 및 여타 사업형태에 대한 적용가능성}

역량개발을 위하여 '적합한 사업을 '효율'적으로 수행함으로써 소기의 '효과’를 거두고, 나아가 파급력(impact)있는 '성과’를 ‘지속 가능’하게 관리하기 위해서는 사업관리의 툴로서 프레임워크가

14) PDM상에서 위험관리는 대개 천재지변, 정치적 변혁 등 사업 외적인 부분의 예상치 못한 위험을 기재하고 있다. 
필요하며,15) 이러한 프레임워크(PPMf)를 활용함으로써 해당사업의 목적과 지표를 일관성있게 관 리할 수 있고 당초 설정한 성과를 달성할 수 있을 것으로 본다.

〈표 2〉 PDM과 PPMf간 주요 차이점 비교

\begin{tabular}{c|c|c}
\hline 구분 & PDM & PPMf \\
\hline 시간 및 단계별 과정 & 시간개념이 없거나 단절, 과정 불분명 & 시간 연속성, 목적달성 단계별 과정 \\
\hline 위험관리 & 외부 위험요소 & 내·외부 위험요소 \\
\hline 수원국과 소통 & 불분명 & 모델수립후 PPMf 작성 등 단계별로 소통 \\
\hline 장점 & 대규모 기획, \\
국가차원의 상위목적 달성 & 모델과 연계, 단계별 목적 \\
\hline
\end{tabular}

출처: 저자작성

'단계별 성과관리 프레임워크(PPMf)'는 PDM과 달리 다음과 같은 장점이 있으므로 $\mathrm{PPMf}$ 를 활 용하여 사업의 성과를 관리할 때에는 이러한 장점을 적극 활용하는 것이 바람직할 것이다. 먼저 보고서 한 장에 사업의 전체(사업의 변화, 시기별 투입, 산출, 목적 등)를 조망할 수 있다는 점은 $\mathrm{PDM}$ 과 유사하다. 그러나 $\mathrm{PDM}$ 과 다른 점은 시간 개념에 따라 투입, 산출 및 목적을 구별하고 있다는 점이다. 또한 목적달성을 위한 단계별 과정을 명확히 하고 있다. 이것은 사업관리에 있어 매우 중요한 사항으로서 시간 경과에 따라 진행되는 사업을 관리하기 위한 툴로서 시간과 사업내 용 및 위험관리 항목간의 완결성을 제고시킬 수 있는 것이다. 목적달성을 위한 단계별 과정을 통 해 각 사업활동의 순차적인 연결고리를 파악함으로써 역량개발을 위한 변화이론(theory of change)과 부합한 관리를 할 수 있을 것이다. 이는 앞서 Sida의 역량개발 변화이론 분석모델에 서 살펴본 바와 같다.

또한, 위험요소를 외부 위험요소 외에도 내부 위험요소까지를 포함하여 투입/산출/지표 및 목 표관리까지 해당되는 위험을 발굴하고, 이를 관리하도록 위험관리 범위를 확장하였다. 또한, 개발 원조에 있어 해당 사업의 목표 달성은 공여국/기관의 단독이 할 수 있는 사안이 아니며, 수원국 과 공동으로 추진하는 것으로서 목적달성을 위한 역할/노력 분담이 필요하다는 것을 명시적으로 사업관리에 반영하였다(Sida, 2015: 118). ${ }^{16)}$ 필요하다면 이를 통해 공여국과 수원국간에 업무분 담을 획정17)할 필요가 있으며, 이를 통해 수원국의 주인의식(ownership)을 제고시킬 수 있다.

15) $\mathrm{OECD/DAC는} \mathrm{개발사업의} \mathrm{평가} \mathrm{지표로서} \mathrm{효율성(efficiency),} \mathrm{적합성(relevance),} \mathrm{효과성(effectiveness),} \mathrm{성과(impact)} \mathrm{및}$ 지속가능성(sustainability) 등 5 가지를 뽑고 있다.

16) Sida의 역량개발 평가결과에 따르면, 공동의 목적을 갖게 되면 역량개발 결과의 달성을 위한 노력을 촉진한다고 한다. (출처: Sida, 2015, Support to Capacity Development).

17) '베트남 감사원 역량강화 지원사업’의 경우 한베 감사원간 업무분장표를 작성하여 활용한 바, 양 기관간 업무분장표를 통해 공통의 성과를 달성하기 위한 역할 분담에 대한 인식을 명확히 할 필요가 있다.(조광걸. 2015. "개발도상국 감사 원 역량강화 지원방안 연구”) 
한편 $\mathrm{PDM}$ 은 상대적으로 협소하고 선형적 인과관계구조를 갖고 있어 이를 활용하여 도출된 인센 티브는 연수생 개인이 속해있는 시스템을 인지하는 대신 훈련기재에 더 신경쓰도록 함으로써 역 량개발 관리기재로 한계가 있다고 지적하고 있다(Sida, 2014: 18). ${ }^{18)}$ 다만, PDM을 국가차원의 개발목표를 달성하기 위한 성과관리 툴로서 활용한다면, 우리나라 무상 및 유상 원조를 포함한 $\mathrm{ODA}$ 를 수원국별 $\mathrm{CPS}$ 에 기초한 거시적인 관리 툴로서 활용할 가치는 있다 할 것이다. KOICA로 서도 다양한 프로젝트와 개발활동을 통합한 프로그램(program) 단위의 성과관리를 위하여 국별 무상원조의 성과관리 툴로서 활용할 수도 있을 것이다.

역량개발뿐 아니라 여타 프로젝트형 사업의 경우에도 근래에는 단년도 사업이거나 단순한 결과 물의 이전보다는 조직차원의 제도개선, 사회적 영향까지를 포함한 목적을 설정하도록 요구하고 있다. 특히 개발에 있어 새로운 사업의 형태가 등장함에 따라 해당사업의 성과관리 확보 또한 새 로운 도전이 될 것이다. 예컨대 개발 원조의 민관협력사업(PPP)의 활성화와 지속가능개발목표 (SDGs)중 예컨대 과학기술, R\&D 부문에 해당하는 사업의 등장은 역량개발에 방점을 두는 개발 원조의 최근 경향과 맞물려 '성과관리를 어떻게 유효하게 할 것인가'하는 숙제를 안고 있다. 이러 한 숙제를 풀어나가는데 상기 시간개념과 내재적 위험 요소를 포함하고 사업의 목적달성 과정 (process)(KOICA, 2012: 46)19)을 명확히 하고 있는 '다년도 성과관리 모델과 프레임워크(MCM, $\mathrm{PPMf})^{\prime}$ 는 매우 유효할 것으로 보인다.

\section{V. 결어}

금년 2016년부터 2030년까지 UN을 위시한 국제사회는 지속가능개발목표(SDGs)를 달성하기 위한 첫걸음을 내딛고 있다. 제프리 삭스(J. Sachs)는 『지속가능한 발전의 시대』에서 "우리는 새 로운 세대에 들어섰다..... 인류의 새로운 세대는 ... 지속가능한 개발목표(SDGs)로 설명될 것이 다“고 언급하면서 개발을 둘러싼 새로운 국면과 도전과제, SDGs의 가치를 설명하고 있다. MDGs 에 비하여 대폭 늘어난 관리범위(8대 목적, 18 개 세부 목표에서 17대 목적, 169 개 목표로 확대) 에 대한 개발행정의 수요는 물론이려니와, 해가 갈수록 증가하고 있는 KOICA 예산과 함께 정체 된 인력사정은 대한민국 $\mathrm{ODA}$ 의 효과성 제고를 위한 걸림돌이자 도전과제이기도 하다.

$\mathrm{OECD}$ 의 개발원조위원회(DAC)는 앞서 살펴본 『개발활동의 평가(evaluating development

18) Sida. Capacity Development Literature Review (2014)에서는 PDM대신 Logical Framework 라고 칭하고 있다.

19) 프로젝트 관리의 함정(Pitfalls of Project Management)의 하나로서 '사업의 목적 달성에 대한 과정이 분명하지 않음'을 지적하고 있다. (출처: KOICA. 2012. “국제사회의 역량개발 지원정책”) 
activities)』에서 12 가지 교훈중 하나로서 원조기관 직원들의 학습문화 형성에 주목하고 있다. "강력한 학습문화를 갖고 있는 기관은 보다 큰 영향력을 갖고 더욱 유연하며 실패할 확률이 적은 데(중략).... 학습문화는 우리의 유일한 실패가 학습의 실패임을 상기시키며 혁신과 위험관리를 장 려한다(OECD, 2013: 12)"고 하고 있다. 또한, 영국 국제개발청(DeFID), 미국의 MCC, EBRD, 캐나다 국제개발청(CIDA), 핀란드 등 북구 3 국의 성과관리와 학습문화 조성 및 제도화를 위한 노 력을 소개하고 있다.

우리나라도 최근 국가협력전략(County Partnership Strategy, CPS)을 수립함에 있어 제1기 $\mathrm{CPS}$ 의 문제점으로 지적되어온 수원국 원조 환경에 대한 심층 분석이 미흡했던 점을 보완하기 위 한 노력을 진행하고 있다. 예컨대 영국 국제개발부(DFID) 등이 사용하고 있는 정치경제분석법 (Political Economy Analysis, PEA)을 활용하여 KOICA식의 분석 툴 마련 가능성이 제안된 바 있다(김수진, 2015).20) 이러한 활동과 더불어 협력사업 각각의 관리 및 개발성과를 위하여 $\mathrm{KOICA}$ 의 업무체계와 현실에 부합한 성과관리 툴에 대한 활발한 논의가 필요하다.

다채로운 개발원조 사업을 효과적으로 관리하여 소기의 목적을 달성하기 위해서 개발행정을 담 당하는 원조기관의 직원들이 부단히 소관 사업에 대해 학습하고 연구할 필요가 있다는 DAC 동료 평가(peer review)의 결론은 169 개의 세부목표(targets)를 담고 있는 지속가능개발목표(SDGs)의 달성을 위해 첫걸음을 띠는 원조기관들에게 매우 시사하는 점이 많다 할 것이다. 본고에서 제안 한 '다년도 역량개발 모델(MCM)'과 '단계별 성과관리 프레임워크(PPMf)'를 계기로 개발원조의 효 과성 제고를 위하여 실제로 도움이 되는 토론과 학습의 전기가 되기를 희망한다.

20) 본 보고서에서는 수원국내 정치경제적 역학관계를 분석함으로써 보다 효과적인 국가협력전략을 도출하기 위하여 DFID, Sida가 활용하고 있는 변화유인법(Drivers of Change)과 파워분석(Power Analysis) 등 정치경제분석법을 소개하고 KOICA 프로그램에 대한 시사점과 제언을 하고 있다. (출처: 김수진. 2015. "정치경제분석법(PEA)에 기반한 국별협력전 략(CPS) 작성 개선 방안 고찰 : DFID와 Sida 사례를 중심으로”). 


\section{〈참고문헌〉}

김수진. 2015. “정치경제분석법(PEA)에 기반한 국별협력전략(CPS) 작성 개선 방안 고찰

: DFID와 Sida 사례를 중심으로”. 성남: 한국국제협력단

조광걸. 2015.『개발도상국 감사원 역량강화 지원방안 연구』. 서울: 감사원

KOICA. 2012.『국제사회의 역량개발 지원정책』. 성남: 한국국제협력단 . 2014, 『연수사업 성과사례집』. 성남: 한국국제협력단 2015. 『글로벌연수 길라잡이』. 성남: 한국국제협력단

KOICA ODA평가실. 2013. 『개발활동의 평가』(OECD, 2013, evaluationg development activities 번역). 성남: 한국국제협력단

KOICA ODA교육원. 2012.『국제개발의 첫걸음』. 성남: 한국국제협력단

Hegarty, A. and Musonda, K., 2012. "Good Practices in Supporting Supreme Audit Institutions". Paris: OECD

Land, A., Greijn, H., Hauck. V, and Ubels, J., 2015. "Reflecting on 25 years of capacity development and emerging trends”. "Capacity Development Beyond Aid』. Phnom Penh: SNV Nethelands Development Organization

Pot, F., 2014. "Synthesis of Evaluation of SAI Capacity Development Programs". Oslo: INTOSAI-Donor Cooperation

Mosley, P. 1986. “Aid-Effectiveness: The Micro-Macro Paradox”. "IDS Bulletin』 vol. 17(2): $22-27$

Otoo, S., Agapitova, N. and Behrens, J., 2009. "The Capacity Development Results Framework: A strategic and results-oriented approach to learning for capacity development”. World Bank Institute, June

Otoo, S., Agapitova, N., Gold, J., and Fisher, S., 2009. "The Need for a Conceptual and Results-based Framework in Capacity Development: Discussion of a New Approach”. ${ }^{\circledR}$ Capacity Development Brief』issue no. 31. Washington D.C.: World Bank

Sida. 2015. "Support to Capacity Development - Identifying Good Practice in Swedish Development Cooperation”. Stockholm: Sida 2014. “Capacity Development Literature Review”. Stockholm: Sida 
Thomas, V., 2006. "Linking Individual, Organizational, and Institutional Capacity Building to Results”. "Capacity Development Brief』vol.19. Washington D.C.: World Bank

Easterly, W., 2011. 『The Elusive Quest for Growth』. Cambridge: The MIT Press

\section{제 I 장}

제 II 장

제 III장

평

가

제 $\mathbb{N}$ 장 


\section{[첨부] '베트남 감사원 역량강화 지원사업의 단계별 성과관리 프레임워크(PPMf) 작성시례}

\begin{tabular}{|c|c|c|c|c|c|}
\hline \multirow{3}{*}{ 구분 } & \multicolumn{3}{|c|}{ 한국측 관리 범위 } & \multicolumn{2}{|l|}{$---\rangle\langle-\quad$ 베트남측 협력 범위 -$\rangle$} \\
\hline & \multirow{2}{*}{\multicolumn{2}{|c|}{$\begin{array}{l}\text { 투입물 } \\
\text { (Input) }\end{array}$}} & \multirow{2}{*}{$\begin{array}{l}\text { 산출물 } \\
\text { (Output) }\end{array}$} & & \multirow{2}{*}{$\begin{array}{c}\text { 성과물 } \\
\text { (Goal/Outcome) }\end{array}$} \\
\hline & & & & (성과관리 수단/지표) & \\
\hline \multirow{3}{*}{$\begin{array}{c}1 \\
\text { 단계 }\end{array}$} & \multicolumn{2}{|c|}{ 현지 워크숍 } & & $\begin{array}{l}\text { - 자료 확보/여부·확보율 } \\
\text { - 베측 발표/발표율,태도 }\end{array}$ & \multirow{3}{*}{$\begin{array}{l}\text { 개인 성과/ } \\
\text { 조직 내 확산. } \\
\text { 시범 적용 }\end{array}$} \\
\hline & 국내연수 & $\begin{array}{l}\text { - 소개 강의 } \\
\text { - 강의·토론 }\end{array}$ & $\begin{array}{l}\text { 실행계획(AP) } \\
\text { 10개안 }\end{array}$ & - 강의·연수 만족도/만족비율 & \\
\hline & 위험관리 & \multicolumn{3}{|c|}{$\begin{array}{l}\text { - 두개 기관대상·내부협조 및 업무분장·커뮤니케이션·적정 연수생 선발·연수기관의 } \\
\text { ODA 이해 }\end{array}$} & \\
\hline \multirow{3}{*}{$\begin{array}{c}2 \\
\text { 단계 }\end{array}$} & \multicolumn{2}{|c|}{ 현지 워크숍 } & 결과보고서 & $\begin{array}{l}\text { - 임원진 브리핑참여/여부·비율 } \\
\text { - AP발표/발표율, 적용사례 }\end{array}$ & $\downarrow$ \\
\hline & 국내연수 & $\begin{array}{l}\text { - 심화강의 } \\
\text { (문제해결형 사례) } \\
\text { - AP 집중토론 }\end{array}$ & $\begin{array}{l}\text { AP 이행과제 } \\
\text { (1 2개/기관별) }\end{array}$ & $\begin{array}{l}\text { • key person지정/여부,적정설 } \\
\text { - AP 소수정예화/집중도 } \\
\text { - 현장사업(pilot project)/수립,실행여부 }\end{array}$ & -7 \\
\hline & 위험관리 & \multicolumn{3}{|c|}{$\begin{array}{l}\text { - 조달시기 }(+1 \mathrm{~m}), \text { 예산집행도 }(70 \%),{ }^{21)} 2 \text { 개 기관대상·내부협조 및 업무분장·커뮤니 } \\
\text { 케이션·적정 연수생 및 key person선발·베측의 솔직한 고민공유·현장사업 형성 } \\
\text { 주도·베측 제도화 여부 }\end{array}$} & $\downarrow$ \\
\hline \multirow{4}{*}{$\begin{array}{l}3 \\
\text { 단계 }\end{array}$} & \multicolumn{2}{|c|}{ 현지 컨설팅 } & 컨설팅보고서 & \multirow{4}{*}{$\begin{array}{l}\text { - 자문관 운영/파견여부 } \\
\text { - key person지정/역할,활동성 } \\
\text { - 현지 컨설팅/여부,성과 }\end{array}$} & \multirow{3}{*}{ 제도 정착 } \\
\hline & 국내연수 & $\begin{array}{l}\text { 사례 강의 } \\
\text { 사례 토론 }\end{array}$ & 제도정착방안 & & \\
\hline & \multicolumn{2}{|c|}{$\begin{array}{c}\text { 컨퍼런스 } \\
\text { (WB초청 국제/양기관) }\end{array}$} & $\begin{array}{l}\text { 성과 발표문, } \\
\text { 보고서 }\end{array}$ & & \\
\hline & 위험관리 & \multicolumn{2}{|c|}{$\begin{array}{l}\text { - 두개 기관대상·자문관 개입정도·key person 적정 운영·베측의 솔직한 고민공 } \\
\text { 유·타임테이블 }\end{array}$} & & $\begin{array}{c}\text { 평가 } \\
\text { (교훈도출) }\end{array}$ \\
\hline
\end{tabular}

출처: 조광걸 (2015) p.72

21) 동 내용은 활용도 예시를 높이기 위해 추후 반영함. 이처럼 핵심 사안에 핵심어만을 기입하고 세부 점검사항은 첨부로 활용하면 보다 세부적이고 통합적인 관리가 가능하다. 